\title{
The effectiveness of treatment for depression/depressive symptoms in adults with cancer: a systematic review
}

S Williams' and J Dale*,I

'Division of Health in the Community, Centre for Primary Health Care Studies, Warwick Medical School, University of Warwick, Coventry CV4 7AL, UK

Depression is common in cancer patients, and this often remains undetected and untreated. Depression has been associated with poorer quality of life, in addition to increased impairment of immune response and poorer survival in cancer patients. Previous systematic reviews and meta-analyses of the efficacy of interventions for cancer patients with depression have failed to distinguish between caseness for depression and depressive symptoms. The findings from this systematic review show that there is limited trial data on the efficacy of prescribed antidepressants in reducing the incidence of major depression and depressive symptoms in cancer patients. Contrary to previous reviews that failed to distinguish between depressive symptoms and depression, this review found very little data from clinical trials (without the possibility of confounding factors) to demonstrate that psychotherapeutic interventions are effective in reducing depression in cancer patients. A number of small-scale, single-centre trials indicated that psychotherapeutic interventions (especially cognitive behavioural therapy) can have effects on depressive symptoms in cancer patients. However, given the methodological limitations of studies to date, lack of evidence should not be interpreted as implying lack of efficacy. In conclusion, there is a need for adequately powered studies of pharmacological and psychotherapeutic studies, which are targeted at cancer patients with a diagnosis of depression and include monitoring of the use of other pharmacological/psychotherapeutic and complementary and alternative medicine interventions.

British Journal of Cancer (2006) 94, 372-390. doi:I0.1038/sj.bjc.6602949 www.bjcancer.com

(c) 2006 Cancer Research UK

Keywords: depression; systematic review; psychotherapeutic interventions; pharmacological interventions

Studies have reported up to $58 \%$ of cancer patients as having depressive symptoms and up to $38 \%$ as having major depression (Massie, 2004). Depression may be particularly difficult to detect in patients suffering from cancer, especially those with terminal illness, and is difficult to distinguish from 'appropriate sadness' related to cancer diagnosis, treatment and the approach of end of life (Lloyd-Williams, 2000; Bailey et al, 2005). There are also difficulties in deciding which somatic symptoms may be attributable to cancer and its consequences, and which may be due to depression (Lloyd-Williams, 2001; Bailey et al, 2005). Psychological distress, including adjustment problems, anxiety and depression, typically occurs at many points along the cancer trajectory, and may be exacerbated by physical pain, the effects of treatment, family difficulties, financial worries, etc. The importance of detecting and treating depressive illness in cancer patients lies not only in the relief of psychological distress and its impact on quality of life but also on consequent health service and societal costs. In addition, depression has been associated with increased impairment of immune response (Andersen et al, 1998; Newport and Nemeroff, 1998; Reiche et al, 2004) and poorer survival (Buccheri, 1998; Faller et al, 1999; Watson et al, 1999; Faller and Bulzebruck 2002; Herjl et al, 2003; Goodwin et al, 2004).

*Correspondence: Professor J Dale; E-mail: Jeremy.Dale@warwick.ac.uk Received 7 November 2005; revised 7 December 2005; accepted 8 December 2005
Psychosocial needs are often inadequately addressed by cancer services, and depression is frequently unrecognised (Newport and Nemeroff, 1998; Passik et al, 1998; Petito and Evans, 1998; LloydWilliams, 2000; Sharpe et al, 2004; Somerset et al, 2004). Clinical practice guidelines for the psychosocial care of cancer patients are available in some countries, such as in the USA and Australia (Turner et al, 2005). The National Institute for Clinical Evidence guidelines for the management of depression in primary and secondary care in the UK propose that screening for depression should be undertaken in primary-care and general hospital settings for high-risk groups, which include those with significant physical illnesses (NICE, 2004).

There have been three recent systematic reviews (Barsevick et al, 2002; Newell et al, 2002; Uitterhoeve et al, 2004) and two metaanalyses (Devine and Westlake, 1995; Sheard and Maguire, 1999) of psychotherapeutic interventions for patients with cancer and depression/depressive symptoms, the results of which provide broad support for such interventions. In their meta-analysis of 98 studies, Devine and Westlake (1995) concluded that psychoeducational care is of benefit to adults with cancer and depression. Likewise, Barsevick et al's (2002) systematic review of 36 studies concluded that psychoeducational interventions reduce depressive symptoms in patients with cancer, and that behaviour therapy or counselling alone or in combination with cancer education is beneficial. However, Sheard and Maguire (1999) in their metaanalysis of 20 trials concluded that preventative psychological interventions in cancer patients do not have a clinical effect upon 
depression. Based on a systematic review of 15 randomised controlled trials, Newell et al (2002) made tentative recommendations about the medium-term benefit of group therapy and the long-term benefits of education and structured counselling. Uitterhoeve et al's (2004) systematic review of 13 trials concluded that psychosocial interventions had positive effects on patients with advanced cancer and depression.

In addition, a meta-analysis by Meyer and Mark (1995) reported on the effects of psychosocial interventions with adult cancer patients in terms of emotional adjustment, which involved measures of such constructs as mood state, fear and anxiety, depression, denial or repression, self-esteem and distress. Although the study did not present findings on efficacy exclusively in terms of depression/depressive symptoms, it found that psychosocial interventions have positive effects on emotional adjustment. There were no significant differences found between types of interventions (behavioural interventions, nonbehavioural counselling and therapy, informational and educational methods, organised social support provided by other patients and other nonhospice interventions). Even so, the authors stated that it would be premature to conclude that there were no differences between treatment categories given the possible confounds.

However, none of these systematic reviews and meta-analyses distinguished between the presence of depressive symptoms and caseness for depression in cancer patients, so limiting their applicability to everyday clinical practice.

There have been no systematic reviews or meta-analyses to date published on the efficacy of antidepressant treatments for cancer patients with depression.

The aim of the following study, therefore, was to systematically review the efficacy of psychotherapeutic and antidepressant interventions for cancer patients with depression/depressive symptoms in terms of (i) reduction in depressive symptoms, (ii) reduction in caseness of clinical depression and (iii) adverse effects.

\section{MATERIALS AND METHODS}

We undertook a systematic review of randomised controlled trials of pharmacological and psychotherapeutic interventions for cancer patients with depression/depressive symptoms. The method was based on established guidelines for conducting systematic reviews (Chalmers and Haynes, 1994; Mulrow, 1994; Oxman, 1994).

\section{Search strategy}

References were retrieved by manual searches and through searching electronic databases. The following electronic databases were searched for years 1995-2005 for psychotherapeutic interventions and 1960-2005 for pharmacological interventions: PubMed, CINAHL, Cochrane Library databases DARE, CDSR, CCTR and PsycARTICLES. Manual searches were conducted and relevant references retrieved from those listed in key papers, reports, theses and dissertations. Box 1 provides the search strategy terms.

\section{Inclusion criteria}

The criteria for selecting studies were randomised controlled trials of pharmacological and psychotherapeutic interventions for depression in cancer patients, published in English. Participants were either adult cancer patients with depression or depressive symptoms receiving a pharmacological or psychotherapeutic intervention for depression/depressive symptoms. Studies investigating the efficacy of psychotherapeutic interventions in the presence of pharmacological therapy (or vice versa) were excluded, as were those evaluating the efficacy of complementary and alternative (CAM) medicine (including meditation) or information/education strategies.

\section{Data extraction and synthesis}

Data extraction was completed independently by the reviewers (SW) and (JD) and checked through for accuracy. Data were gathered using a data extraction form (Appendix A). The main outcomes were either depressive symptoms or diagnosed clinical depression measured by a separate scale or as part of a composite outcome measure. Study quality was assessed with the Methodological Quality Instrument (Appendix A) developed by Cho and Bero (1994). Studies were assessed as being of low methodological quality if they failed to meet the minimum requirements on each of the following aspects of study design: adequacy of sample size, randomisation, blinding, method of allocation concealment, clear description of treatment, representative source of subjects, use of diagnostic criteria, number of and reasons for withdrawal from intervention and how dealt with in the analysis, outcome measures described clearly, use of validated instruments, and steps taken to control for possible confounding factors.

\section{RESULTS}

\section{Study inclusion and characteristics}

Figure 1 shows the numbers of studies yielded by the search strategy. In all, 29 papers reporting pharmacological studies and 63 reporting psychotherapeutic interventions were identified as potentially relevant and were carefully read. Of these, we excluded 65 because they did not meet the inclusion criteria, and a further two were excluded because they were not strictly randomised controlled trials (Holland et al, 1998; Kissane et al, 2003) and one because it failed to measure baseline levels of depressive symptoms (Stiegelis et al, 2004). This left a total of 24 studies (Table 1), of which six were trials of pharmacological treatments and 18 were of psychotherapeutic interventions.

\section{Pharmacological studies}

The six pharmacological studies were randomised placebocontrolled trials conducted in the United States of America $(n=4)$ (Musselman et al, 2001; Fisch et al, 2003; Morrow et al, 2003; Roscoe et al, 2005) and Belgium $(n=2)$ (Razavi et al, 1996;

Box I Search strategy terms

Search terms were taken from known articles relevant to the review and the Medical Subject Headings (MeSH) thesaurus of the US National Library of Medicine (NLM). The search terms included: 'Depression'; 'Depressive Disorder'; 'Depressive Disorders'; 'Disorder, Depressive'; 'Disorders, Depressive'; 'Neurosis, Depressive'; 'Depressive Neuroses'; 'Depressive Neurosis'; 'Neuroses, Depressive'; 'Melancholia'; 'Melancholias'; 'Unipolar Depression'; 'Depression, Unipolar'; 'Depressions, Unipolar'; 'Depression, Endogenous'; 'Depressions, Endogenous'; 'Endogenous Depression'; 'Endogenous Depressions'; 'Depressive Syndrome'; 'Depressive Syndromes'; 'Syndrome, Depressive'; 'Syndromes, Depressive'; 'Depression, Neurotic'; 'Depressions, Neurotic'; 'Neurotic Depression'; 'Neurotic Depressions'; 'Depressions'; 'Depressive Symptoms'; 'Depressive Symptom'; 'Symptom, Depressive'; 'Symptoms, Depressive'; 'Emotional Depression'; 'Depression, Emotional'; 'Depressions, Emotional'; 'Psychiatric Morbidity'; 'Psychological Morbidity'; 'Cancer'; 'Neoplasms'; 'Neoplasms, Second Primary'; 'Hypothalamic Neoplasms'; 'Brain Neoplasms'; 'Brain Stem Neoplasms'; 'Head and Neck Neoplasms'; 'Spinal Cord Neoplasms'; 'Meningeal Neoplasms'; 'Urologic Neoplasms'; 'Cerebellar Neoplasms'; 'Supratentorial Neoplasms'; 'Unrogenital Neoplasms'; 'Sigmoid Neoplasms';

'Infratentorial Neoplasms'; 'Cerebral Ventricle Neoplasms'; 'Testicular Neoplasms'; 'Pharyngeal Neoplasms'; 'Pelvic Neoplasms'; 'Ovarian Neoplasms'; 'Breast Neoplasms'; 'Antidepressive Agents'; 'Antidepressive Agents - adverse effects'; 'Serotonin Uptake Inhibitors'; 'Fluoxetine'; 'Cognitive Therapy'; 'Randomised Controlled Trials' 


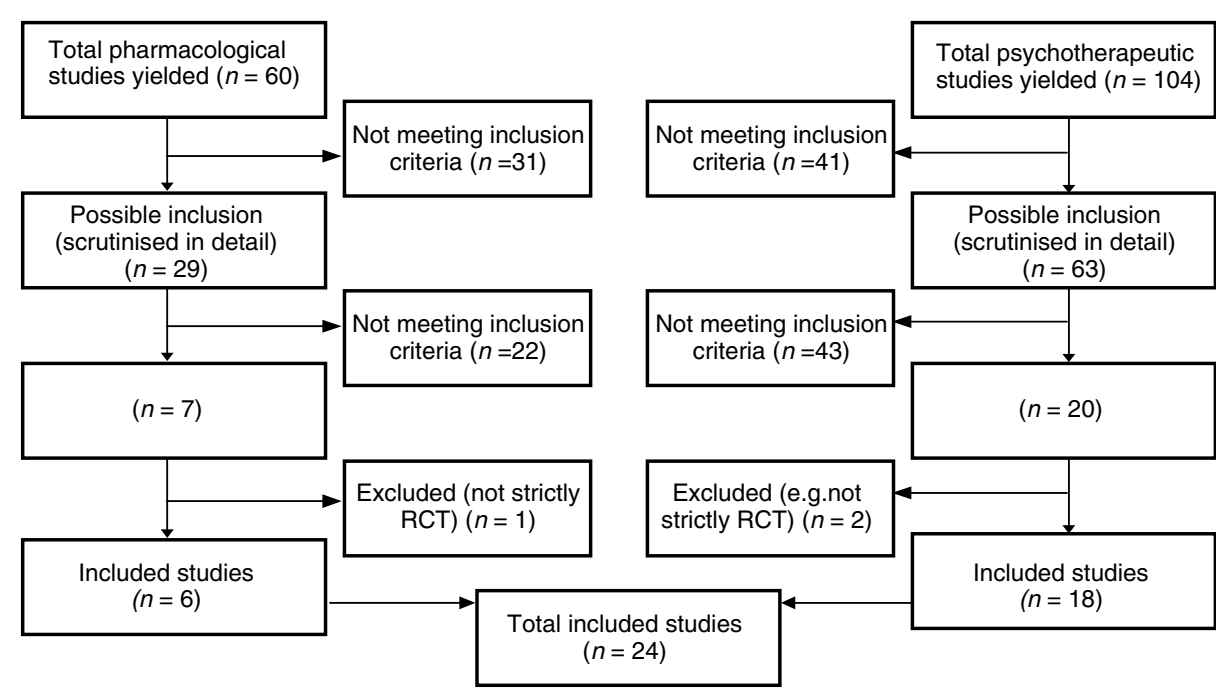

Figure I Number of studies yielded by search strategy.

Van Heeringen and Zivkov, 1996). The mean sample size of intervention and control groups was 83 (range 20-277 patients) and 83 (range 20-272 patients), respectively. The average age of patients ranged from 50 to 61 years. Between half to $100 \%$ of participants were female. Three studies were multicentre trials (Razavi et al, 1996; Fisch et al, 2003; Morrow et al, 2003) and three were single-centre trials (Van Heeringen and Zivkov, 1996; Musselman et al, 2001; Roscoe et al, 2005).

Methodological quality The methodological quality of these trials is summarised in Table 2. The sample size exceeded 100 patients in two of the six (33\%) trials (Fisch et al, 2003; Morrow et al, 2003). The method of randomisation to groups was sufficiently well described in all studies, but the method of allocation concealment was adequately described in only four trials (Razavi et al, 1996; Musselman et al, 2001; Fisch et al, 2003; Roscoe et al, 2005). Blinding of investigators was reported in five trials (Razavi et al, 1996; Van Heeringen and Zivkov, 1996; Musselman et al, 2001; Fisch et al, 2003; Roscoe et al, 2005) and blinding of subjects in all trials. All studies provided a clear description of the intervention, had a representative source of subjects and provided the number and reasons for withdrawals. Dropout rates for intervention and controls ranged from 0 to $56 \%$. Three trials stated that intentionto-treat analyses were used to deal with patients who were lost to follow-up (Razavi et al, 1996; Van Heeringen and Zivkov, 1996; Musselman et al, 2001).

Two trials selected subjects on the basis of a depressive disorder using Diagnostic and Statistical Manual of Mental Disorders, third edition (DSM-III) criteria (Razavi et al, 1996; Van Heeringen and Zivkov, 1996); one selected patients who were to receive high-dose alpha therapy (which has been associated with symptoms of major depression) (Musselman et al, 2001). Three trials reported on the efficacy of the pharmacological treatment in terms of caseness for depression (Razavi et al, 1996; Musselman et al, 2001; Roscoe et al, 2005) with the other three trials reporting on change in the level of depressive symptoms as indicated by scores on questionnaires (Van Heeringen and Zivkov, 1996; Fisch et al, 2003; Morrow et al, 2003). All outcome measures were clearly described and were valid and reliable (Table 1).

Five trials investigated the efficacy of selective serotonin reuptake inhibitors with three investigating paroxetine (Musselman et al, 2001; Morrow et al, 2003; Roscoe et al, 2005) and two fluoxetine (Razavi et al, 1996; Fisch et al, 2003), while the remaining study investigated the tricyclic antidepressant mianserin (Van Heeringen and Zivkov, 1996). All six trials avoided/monitored pharmacological cointerventions by trial design. None of the six studies reported avoiding or monitoring the use of potentially confounding psychotherapeutic or CAM cointerventions by subjects during the study periods.

\section{Effectiveness and tolerability}

Depression: One trial found paroxetine effective in reducing major depression in cancer patients with malignant melanoma who were to receive high-dose interferon alpha therapy (Musselman et al, 2001). Major depression developed in 11\% (two of 18) of the paroxetine and $45 \%$ (nine of 20 ) of the placebo group, and $5 \%$ of paroxetine compared to $35 \%$ of the placebo group had to discontinue interferon alpha because of severe depressive distress. In terms of tolerability, retinal haemorrhages developed in three patients (severely in one patient) who were taking paroxetine. The sample size was only 40 patients, but no subjects withdrew from the study.

Another trial found paroxetine to be effective in reducing caseness for depression in breast cancer patients receiving chemotherapy (Roscoe et al, 2005). At final follow-up (cycle 4 of chemotherapy), only four of the original 13 patients $(31 \%)$ in the paroxetine group who had baseline depression (scoring greater than 19 on the Center for Epidemiological Studies Depression scale) had scores above the cutoff, while all $13(100 \%)$ of the initially depressed patients in the placebo group remained above the threshold. Dropout rates were comparable for intervention and controls ( 25 and $21 \%$, respectively).

Fluoxetine was not effective in reducing caseness for depression in a trial that included patients with breast, gynaecological or haematological cancer who presented with major depressive disorder (Razavi et al, 1996). The successful response rate (defined by Hospital Anxiety and Depression Scale (HADS) score lower than 8 after 5 weeks of treatment) was not significantly higher $(11 \%)$ in the intervention group than the placebo group (7\%). Side effects between groups were not significantly different, although there was a trend towards digestive and neuropsychiatric adverse events in the intervention group. There were, however, significantly more dropouts from the intervention group $(33 \%)$ compared with controls $(15 \%)(P=0.04)$.

Depressive symptoms: Paroxetine was found to be effective in reducing depressive symptoms in breast, lung, haematological, gynaecological and gastrointestinal cancer patients who reported fatigue at their second chemotherapy cycle (Morrow et al, 2003). Dropout rates were comparable for intervention and controls 
Table I Characteristics of included studies $(n=24)$

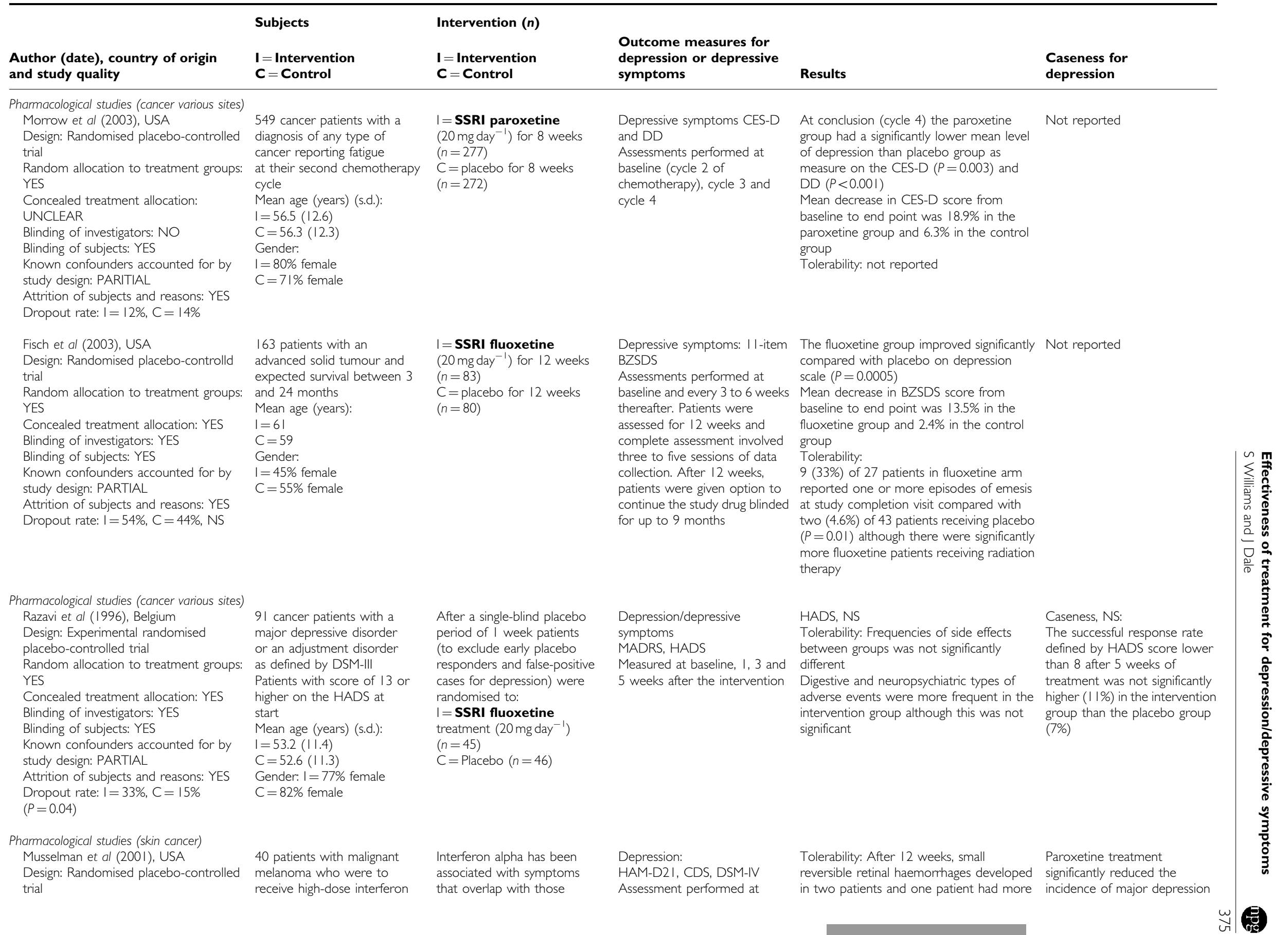

\section{Clinical Studies}


Table I (Continued)

\section{Subjects \\ I = Intervention \\ C $=$ Control \\ Intervention (n)}

\section{Author (date), country of origin}

and study quality alpha therapy

Random allocation to treatment groups: YES

Concealed treatment allocation: YES Blinding of investigators: YES Blinding of subjects: YES Known confounders accounted for by study design: PARTIAL

Attrition of subjects and reasons: YES

Dropout rate: $\mid=0 \%, C=0 \%$ we

$C=50.1(13.4)$

Gender:

I= $50 \%$ female

C $=50 \%$ female

weeks before the initiation

interferon alpha therapy SSR

Paroxetine ( $10 \mathrm{mg}_{\text {day }}-1$
tablet) for one week

tablet) for one week
(20 $\mathrm{mg}^{-1}$ day $^{-1} 2$ tablets) fo one week. Four weeks after

the initiation of paroxetine

therapy the dosage could

be increased up to

$40 \mathrm{mg} \mathrm{day}^{-1} 4$ tablets $)(n=20)$

$C=$ placebo therapy $(n=20)$

Pharmacological studies (breast cancer)

Roscoe et al (2005), USA

Design: Randomised placebo-controlled

trial four cycles of chemotherapy

Random allocation to treatment groups: and not undergoing

YES concurrent radiation or

Concealed treatment allocation: YES

Blinding of investigators: YES

Blinding of subjects: YES

study design: PARTIAL

Attrition of subjects and reasons: YES

Dropout rate $\mathrm{I}=25 \%, \mathrm{C}=21 \%$

Van Heeringen and Zivkov (1996),

Belgium

Design: Experimental randomised

placebo-controlled trial

Random allocation to treatment groups: YES

Concealed treatment allocation:

UNCLEAR

Blinding of investigators: YES

Blinding of subjects: YES

Known confounders accounted for by study design: PARTIAL

Attrition of subjects and reasons: YES

Dropout rate: $I=21 \%, C=56 \%$

$(P=0.014)$

Psychotherapeutic studies (cancer various sites) Kuijer et al (2004), The Netherlands

Design: Experimental randomised

controlled trial

Random allocation to treatment

groups: YES
59 couples with medical diagnosis of cancer in one partner with an estimated life expectancy of at least 6 months for the ill partner
Mean age (years) (s.d.)

$I=52.2(9.3)$

$C=52.2(10.2)$

\section{I = SSRI paroxetine}

$\left(20 \mathrm{mg} \mathrm{day}^{-1}\right)$ for four cycles

of chemotherapy $(n=44)$

$\mathrm{C}=$ placebo for four cycles

of chemotherapy $(n=50)$

55 women with breast cance (stage I or stage II without metastases) with a diagnosis of depression according to

$I=5 I(8)$
$C=53(8)$

\section{I = TCA mianserin} treatment: I week

$30 \mathrm{mg} \mathrm{day}^{-1}$, then

$60 \mathrm{mg} \mathrm{day}^{-1}(n=28)$
$C=$ Placebo $(n=27)$
I = CBT: brief counselling focused on the exchange of social support and help between both partners. Five

Outcome measures for

depression or depressive

symptoms

\section{Results}

ness for scheduled intervals after the intiation of interferon alpha therapy for the first 12 weeks of a planned 48-week treatment period.

severe retinal haemorrhages with associated irreversible loss of vision. All three patients were taking paroxetine. Retinal haemorrhage is a rare side effect of two of the 18 (1 1\%) patients in paroxetine and high rates of retinal complications occur in patients treated with the 20 (45\%) patients in the interferon alpha. Paroxetine significantly decreased the likelihood that interferon alpha therapy would be discontinued because of severe depression or related neurotoxic effects $(P=0.03)$

Depression/depressive symptoms CES-D and DD

Depressive symptoms HAM-D2I

Measured at 14,28 and

42 days after treatment

Depressive symptoms $=$ Once before intervention, 1 intervention $(P<0.05)$. ES $=0.55$

week postintervention and 3 Mean decrease in CES-D score for patients months postintervention from baseline to end point was $31.7 \%$
Paroxetine was more effective than placebo in reducing depressive symptoms during chemotherapy as measured by the CES-D $(P=0.006)$ and the DD $(P=0.07)$ Mean decrease in CES-D score from baseline to end point was $40 \%$ in the paroxetine group and $14 \%$ in the control group

Tolerability: Not reported

By cycle 4, only four of the original 13 patients in the paroxetine group who had baseline CES-D scores greater than 19 still had scores above that cutoff point. This compares to all 13 of the initially depressed patients in the placebo group remaining above threshold.

There were significantly lower HAM-D2I scores for the mianserin group at 28 days $(P=0.004)$ and 42 days $(P=0.004)$

Tolerability: No significant differences were found between numbers of patients complaining of at least one adverse event at changes were seen in vital signs 
Table I (Continued)

\begin{tabular}{|c|c|c|c|c|c|}
\hline $\begin{array}{l}\text { Author (date), country of origin } \\
\text { and study quality }\end{array}$ & $\begin{array}{l}\text { Subjects } \\
\text { I= Intervention } \\
\text { C }=\text { Control }\end{array}$ & $\begin{array}{l}\text { Intervention (n) } \\
\text { I= Intervention } \\
\text { C = Control }\end{array}$ & $\begin{array}{l}\text { Outcome measures for } \\
\text { depression or depressive } \\
\text { symptoms }\end{array}$ & Results & $\begin{array}{l}\text { Caseness for } \\
\text { depression }\end{array}$ \\
\hline $\begin{array}{l}\text { Concealed treatment allocation: } \\
\text { UNCLEAR } \\
\text { Blinding of investigators: NO } \\
\text { Blinding of subjects: NO } \\
\text { Known confounders accounted for by } \\
\text { study design: NO, cointerventions } \\
\text { not reported } \\
\text { Attrition of subjects and reasons: YES } \\
\text { Dropout rate: I=37.5\%, C=40.7\% }\end{array}$ & $\begin{array}{l}\text { Mean age (years) (s.d.): } \\
\text { I= Patient } 50(12) \\
\text { C= Patient } 49(10) \\
\text { Gender patient: } \\
\text { I=70\% female } \\
\text { C }=68 \% \text { female }\end{array}$ & $\begin{array}{l}90 \text { min sessions led by a } \\
\text { psychologist held biweekly. } \\
\text { The approach was cognitive- } \\
\text { behaviourally oriented } \\
(n=20) \\
C=\text { waiting list group } \\
(n=19)\end{array}$ & $\begin{array}{l}12=\text { twice before intervention, } \\
\text { I week postintervention } \\
\text { and } 3 \text { months } \\
\text { postintervention }\end{array}$ & $\begin{array}{l}\text { in the experimental group and }-7.6 \% \\
\text { in the waiting list group }\end{array}$ & \\
\hline $\begin{array}{l}\text { Given et al (2004), USA } \\
\text { Design: Experimental randomised } \\
\text { controlled trial } \\
\text { Random allocation to treatment groups: } \\
\text { YES } \\
\text { Concealed treatment allocation: } \\
\text { UNCLEAR } \\
\text { Blinding of investigators: NO } \\
\text { Blinding of subjects: NO } \\
\text { Known confounders accounted for by } \\
\text { study design: NO, cointerventions not } \\
\text { reported } \\
\text { Attrition of subjects and reasons: } \\
\text { attrition, but no reasons given } \\
\text { Dropout rate: I= } 32 \%, C=27 \%\end{array}$ & $\begin{array}{l}237 \text { patients diagnosed } \\
\text { with a solid tumour and } \\
\text { within } 56 \text { days of undergoing } \\
\text { a first cycle of chemotherapy } \\
\text { Mean age (years): } \\
I=59.3 \\
C=61.2 \\
\text { Gender: } \\
\text { Approx } 80 \% \text { female }\end{array}$ & $\begin{array}{l}\text { I=CBT: I0 contact (I h } \\
\text { sessions), } 20 \text { week } \\
\text { experimental group cognitive } \\
\text { behavioural approach for } \\
\text { symptom management. Each } \\
\text { strategy for addressing a } \\
\text { symptom problem was } \\
\text { evaluated at follow-up with } \\
\text { the patient. If the strategy } \\
\text { had been tried and was } \\
\text { effective it was retained } \\
\text { and if not new strategies } \\
\text { were introduced }(n=\mid 18) \\
C=\text { conventional care } \\
(n=119)\end{array}$ & $\begin{array}{l}\text { Depressive symptoms - } \\
\text { CES-D } \\
\text { Baseline, } 10 \text { and } 20 \text { weeks }\end{array}$ & $\begin{array}{l}\text { The intervention had a short-term } \\
\text { ( } 10 \text { weeks) but no long-term } \\
\text { ( } 20 \text { weeks) effect on patient } \\
\text { depressive symptoms ( } E S=0.25-0.33 \\
\text { at } 10 \text { and } 20 \text { weeks, respectively) } \\
\text { The intervention was more effective in } \\
\text { lowering depressive symptoms at } \\
10 \text { weeks among patients with higher } \\
\text { levels of baseline symptom severity. } \\
\text { Among patients with high levels of } \\
\text { baseline depression, the intervention } \\
\text { was less successful in lowering } \\
\text { depressive symptoms at } 10 \text { weeks } \\
\text { than the conventional care control } \\
\text { group alone }\end{array}$ & Not reported \\
\hline \multicolumn{6}{|l|}{ Psychotherapeutic studies (cancer various sites) } \\
\hline $\begin{array}{l}\text { Rawl et al (2002), USA } \\
\text { Design: Experimental randomised } \\
\text { controlled trial } \\
\text { Random allocation to treatment } \\
\text { groups: YES } \\
\text { Concealed treatment allocation: YES } \\
\text { Blinding of investigators: NO } \\
\text { Blinding of subjects: NO } \\
\text { Known confounders accounted for } \\
\text { by study design: NO, cointerventions } \\
\text { not reported } \\
\text { Attrition of subjects and reasons: YES } \\
\text { Dropout rate: I=38\%, C=19\% }\end{array}$ & $\begin{array}{l}\text { I09 patients newly diagnosed } \\
\text { with breast, colon or lung } \\
\text { cancer who were receiving } \\
\text { chemotherapy } \\
\text { Mean age (years) (s.d.): } \\
55.7 \text { (II.9) } \\
\text { Gender: } \\
\text { I= } 87 \% \text { female } \\
\text { C }=73 \% \text { female }\end{array}$ & $\begin{array}{l}\text { I = Computer-based } \\
\text { assessment and } \\
\text { individually tailored } \\
\text { care plans: A menu-driven } \\
\text { computer program that } \\
\text { guided clinical assessment, } \\
\text { problem identification, } \\
\text { selection of interventions } \\
\text { and measurement of } \\
\text { outcome. For each } \\
\text { symptom or problem } \\
\text { exhaustive problem-specific } \\
\text { lists of appropriate } \\
\text { interventions were available. } \\
\text { Nurse specialists could } \\
\text { input assessments of } \\
\text { patients' physical and } \\
\text { psychosocial functioning } \\
\text { (including anxiety and } \\
\text { depression) and symptom } \\
\text { experience. It allowed for } \\
\text { individual tailoring of care } \\
\text { plans. Nurses also provided }\end{array}$ & $\begin{array}{l}\text { Depressive symptoms } \\
\text { CESD-20 } \\
\text { Measured at baseline, time } 2 \\
\text { midway through intervention } \\
\text { and time } 3 \text { one month } \\
\text { postintervention ( } 24 \text { weeks) }\end{array}$ & $\begin{array}{l}\text { Patients who received the intervention } \\
\text { had significantly fewer symptoms } \\
\text { between baseline and time } 2 \text {. } \\
\text { CESD-20 at time } 2(P=0.05)\end{array}$ & Not reported \\
\hline
\end{tabular}


Table I (Continued)

\begin{tabular}{l} 
Author (date), country of origin \\
and study quality \\
\hline \\
McLachlan et al (200I), Australia \\
Design: Experimental randomised \\
controlled trial \\
Random allocation to treatment \\
groups: YES \\
Concealed treatment allocation: YES \\
Blinding of investigators: NO \\
Blinding of subjects: NO \\
Known confounders accounted for \\
by study design: NO, cointerventions \\
not reported \\
Attrition of subjects and reasons: YES \\
Dropout rate: I=28\%, C=31\%
\end{tabular}

Psychotherapeutic studies (breast cancer) Evans and Connis (1995), USA Design: Experimental randomised controlled trial

Random allocation to treatment groups: YES

Concealed treatment allocation: NO Blinding of investigators: NO

Blinding of subjects: NO

Known confounders accounted for by study design: NO, cointerventions not reported

Attrition of subjects and reasons: YES Dropout rate: $8 \%$ overall
Intervention ( $n$ )

C $=$ Control

\section{Subjects}

I = Intervention

C $=$ Control

450 cancer patients

The authors stated that

patient demographics were

well balanced in the two arms. Median age (years) (range):6

(18-92)

$41 \%$ female

ard
I = Intervention

Outcome measures for

depression or depressive

symptoms

emotional support and

counselling during each

session $(n=55)$

$\mathrm{C}=$ standard care

$(n=54)$

\section{I = Computer-based \\ assessment and}

individually tailored

care plans: A computer-

generated one-page summary

of the questionnaire results

(CNQ, EORTC QLQ-30, BDI)

was made available immediately

for consideration during the

consultation with the doctor.

After discussion with the

doctor and patient the co-

ordination nurse formulated

an individualised management

plan $(n=296)$

$C=$ conventional clinical

encounter $(n=154)$

78 stage II depressed cancer patients receiving radiation treatment

Mean age (years):

II $=54.2$

$12=53.7$
$C=53.8$

$\mathrm{C}=53.8$

Gender:

II $=37 \%$ female

$12=33 \%$ female

C $=33 \%$ female

\section{I = CBT: Cognitive-}

Depressive symptoms CES-D and SCL-90-R measured at baseline, 8 weeks and 6 months behavioural treatment

(8 week) led by a social

worker with more than 10

years of group counselling

experience. Group sessions

lasted I h per week and had

six to nine participants. The

focus was on cognitive and

behavioural strategies to

reduce maladaptive anxiety

and depression $(n=29)$

12 = Social support: Social

support ( 8 week) led by a social

worker with more than 10

years of group counselling

experience. Group sessions

lasted I h per week and had

six to nine participants. The

leader encouraged members

to describe their feelings

about having cancer, to

identify shared problems, to

discuss how these are

discuss how these are

\section{Depression/depressive} symptoms

$\mathrm{BDI}$-short form

Measured at baseline, 2 and 6

months after intervention or severely depressed at baseline, significant of patients who were reduction in depression at 6 months

$$
(P=0.00 \mathrm{I})
$$
respectively
Caseness for

depression
Subjects who received either cognitive behavioural or social support group

interventions had significantly lower

CES-D scores than controls at 8 weeks $(P<0.0 \mathrm{I})$ and at 6 months social support group interventions had significantly lower CES-D scores than controls $(P<0.01)$.

Mean decrease in CES-D score for

patients from baseline to 6 months was $11 \%$ for the cognitive behavioural group $29 \%$ for the social support group and $14 \%$ in the control group
Not reported depressed at baseline were still so, whereas in the intervention arm, there were 58 and $45 \%$, 
Table I (Continued)

\begin{tabular}{l} 
Author (date), country of origin \\
and study quality \\
\hline \\
Winzelberg et al (2003), USA \\
Design: Experimental randomised \\
controlled trial \\
Random allocation to treatment \\
groups: YES \\
Concealed treatment allocation: NO \\
Blinding of investigators: NO \\
Blinding of subjects: NO \\
Known confounders accounted for \\
by study design: NO, cointerventions \\
not reported \\
Attrition of subjects and reasons: YES \\
Dropout rate: $19 \%$ overall
\end{tabular}

Subjects

I = Intervention
C = Control

Intervention ( $\boldsymbol{n})$

I = Intervention

C = Control

supportive roles $(n=23)$

$\mathrm{C}=$ No treatment contro

$(n=26)$

72 women with primary

breast carcinoma

Mean age (years)

(s.d.): 49.5 (6.2)

There were no baseline

differences between groups

I=Social support/

topics and related concerns.

Psychotherapeutic studies (breast cancer) Antoni et al (200I), USA

Design: Experimental randomised controlled trial

Random allocation to treatment

groups: YES

Concealed treatment allocation: NO

Blinding of investigators: NO

Blinding of subjects: NO

Known confounders accounted for

by study design: NO, cointerventions

not reported

Attrition of subjects and reasons:

attrition but not reason: Dropout

rate: $26 \%$ overall

Goodwin et al (200I), Canada Design: Experimental randomise controlled trial

Random allocation to treatment groups: YES
100 women newly treated for stage 0 - II breast cancer Mean age (years) (s.d.):

$I=48.1(9.0)$

$\mathrm{C}=52.1(9.0)$

235 women with metastatic breast cancer who were expected to survive at least 3 months

Mean age (years) (s.d.): and planning) and emotion-

Outcome measures for

depression or depressive

symptoms

Results

Caseness for

depression

education: web-based

psychoeducational support

group, 12 weeks. The program

introduced a new topic related

to breast cancer each week and

the mental health professional

facilitated a discussion on these

On the website participants

were able to read personal

stories from survivors, share

their own experiences and

keep a private web-based

personal journal. Participants

wrote a brief description of

how they were feeling when

they logged on $(n=36)$

$C=$ Wait-list control $(n=36)$

Depressive symptoms

CES-D

Measured at baseline and at

2 weeks)

I = CBT: | |0-week group cognitive behavioural stress management intervention. Weekly for ten 2-h sessions.

It included both problem-

focused (e.g. active coping

focused (e.g. relaxation

training, use of emotional

support) coping strategies

$(n=47)$

\section{$\mathrm{C}=$ Education/}

information: One-day group seminar approximately 16-18 weeks postsurgery. To provide at least of the topics covered by on al intervention condition $(n=53)$

I= CBT: Weekly supportive expressive group therapy (90 min sessions) for at least one year. Groups consisted of $8-12$ women and two
POMS 4,8 and 12 months after randomisation
Depressive symptoms POMS, CES-D

Measured at baseline,

post-intervention (3 months),

3 months and 9 months

POMS, NS

CES-D In the intervention group the

Not reported proportion of women meeting criteria for moderate levels of depressive symptoms

postintervention, 6 months and 12 months $(P<0.04)$

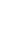

POMS Depression dejection was significantly lower in the intervention group

$(P=0.002)$ I year after randomisation

The psychological intervention was

not associated with prolonged survival
Not reported

Mean decrease in $C E S-D$ score for patients from baseline to 12 weeks was $36 \%$ in the experimental group and $4 \%$ in the control

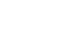


Table I (Continued)

Intervention (n)

Subjects

I = Intervention

$\mathbf{C}=$ Control

\section{I = Intervention}

C $=$ Control

leaders. A monthly $90 \mathrm{~min}$

session was provided for

family and friends $(n=158)$

\section{$C=$ Education $/$}

information: Education

materials only. No supportive-

expressive group therapy

intervention $(n=77)$

Psychotherapeutic studies (breast cancer)

Classen et al (200I), USA

Design: Experimental randomised

controlled trial

Random allocation to treatment

groups: YES

Concealed treatment allocation: NO

Blinding of investigators: NO

Blinding of subjects: $\mathrm{NO}$

Known confounders accounted for

by study design: $\mathrm{NO}$, cointerventions

not reported

Attrition of subjects and reasons: YES

Dropout rate: $18 \%$ overall

Fukui et al (2000), Japan

Design: Experimental randomised

controlled trial

Random allocation to treatment

groups: YES

Concealed treatment allocation: $\mathrm{NO}$

Blinding of investigators: NO

Blinding of subjects: $\mathrm{NO}$

Known confounders accounted for

by study design: NO, cointerventions

not reported

Attrition of subjects and reasons: YES

Dropout rate: $8 \%$ overall

Sandgren et al (2000), USA

Design: Experimental randomised

controlled trial

Random allocation to treatment

groups: YES

Concealed treatment allocation: NO

Blinding of investigators: NO

Blinding of subjects: NO

Known confounders accounted for

by study design: NO, cointerventions

not reported
125 women with metastatic breast cancer

Mean age (years) (s.d.)

$I=52.9(\mid 0.7)$

$C=54.0(10.7)$

50 women with primary

breast carcinoma

Mean age (years) (s.d.)

$I=52.6(6.8)$
$C=54.3(7.5)$

53 women newly

diagnosed with stage I or ||

breast cancer

Mean age (years) (s.d.)

$51.23(12.5)$

\section{I = CBT: Individual}

students by telephone. There

\section{Outcome measures fo}

depression or depressive

symptoms

Results

Caseness for

depression

I = CBT/education: | year

of weekly (90 min sessions)

of supportive-expressive

group therapy and educatio

materials. The treatment

strategy is to facilitate

discussion of issues that are

uppermost in the patients

minds rather than imposing

topics to be discussed ( $n=64$ )

\section{$C=$ Education/}

\section{information: Education}

materials only $(n=61)$

I= CBT: Six group sessions of structured psychosocia intervention with a cognitive-

behavioural approach. It

included health education

coping skills training, stress

management and psychological

support ( $n=25$ )

$C=$ Wait-list control $(n=25)$
Depressive symptoms

Measured at baseline and

every 4 months during the first year

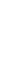

When follow-up assessments undertaken

within I year of the patients' death

were excluded in the secondary

analyses POMS Depression subscale

was significantly lower for the treatment group, $E S=0.27$
Not reported

symptoms

6 month
HADS, POMSMeasured

Depressive symptoms

psychosocial therapy (cognitive POMS

behavioural) delivered by three Measured at baseline, I, 4

female psychology graduate

and 10 months

were a total of ten therapy

sessions (average duration

$20-25 \mathrm{~min}$ ) once a week for

4 weeks and then every other

week for six more sessions. The

intervention focused on four 
Table I (Continued)

\section{Author (date), country of origin \\ and study quality}

Attrition of subjects and reasons: YES

Dropout rate: $15 \%$ overall
Subjects

I = Intervention

C $=$ Control
Intervention (n)

\section{I = Intervention}

C $=$ Control

\section{Outcome measures for}

depression or depressive

symptoms
Results

Caseness for

depression

areas: providing support,

teaching coping skills, managing

anxiety and stress and helping

to solve patient generated

problems. $(n=24)$

$\mathrm{C}=$ No therapy control

$(n=29)$

Psychotherapeutic studies (breast cancer) Edelman et al (1999), Australia

Design: Experimental randomised

controlled trial

Random allocation to treatment groups: YES

Concealed treatment allocation: NO

Blinding of investigators: NO

Blinding of subjects: NO

Known confounders accounted for

by study design: $\mathrm{NO}$, cointerventions

not reported

Attrition of subjects and reasons:

Attrition but no reasons Dropout

rate: $23 \%$ overall

Marchioro et al (1996), Italy

Design: Experimental randomised

controlled trial

Random allocation to treatment

groups: YES

Concealed treatment allocation: NO

Blinding of investigators: NO

Blinding of subjects: NO

Known confounders accounted for

by study design: NO, cointerventions

not reported

Attrition of subjects and reasons: NO

McArdle et al (1996), UK

Design: Experimental randomised

controlled trial

Random allocation to treatment

groups: YES

Concealed treatment allocation: NO
124 women with metastatic breast cancer

Mean age (years) (range): 50 (29-65)

There were no significant

differences in age between groups

36 newly diagnosed women with non-metastatic breast cancer assigned to adjuvant chemotherapy after surgery Median age (years):

$1=53$

$C=52$

272 women undergoing surgery for breast cance Median age (years)

II $=59$

$12=55$
I= CBT: Group cognitive

Depressive symptoms

behaviour therapy. Eight weekly POMS

sessions of group CBT followed Measured at baseline, after by a family night and three completion of therapy, 3 further monthly sessions. The months and 6 months

therapy incorporated the use of

cognitive and behaviour

techniques as well as

encouraging the expression of

feeling and building of group

support $(n=62)$

$\mathrm{C}=$ No therapy contro

$(n=62)$

\section{I = Counselling/}

psychotherapy: Weekly

50 min individual cognitive

individual psychotherapy and

bimonthly family counselling

with a psychologist. Cognitive

psychotherapy was aimed at

analysis and relief of major

problems related to cancer

diagnosis and therapy: anxiety

and/or depression, loss of

behavioural and emotiona

control, altered cognitive

functioning, social and role

limitations and physiological

symptoms $(n=\mid 8)$

$C=$ Standard follow-up

$(n=18)$

II = routine care plus

education/information/

Depressive symptoms

counselling/support from

MQ-28, HADS

from Measured at I, 3,6 and I2

breast care nurse: routine months after surgery

care (including information

booklet) plus support from
Depressive symptoms

Measured at baseline and after I, 3, 6 and 9 months

Depression scores improved significantly over time in the intervention group $(\mathrm{ES}=0.27)$
After completion of therapy significant improvement in depressive symptoms $(P=0.008)$

Not reported

Not reported

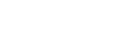

GHAD

Scores were lower in patients offered support from breast care nurse alone (II)

(

Severe depression $(P=0.003)$ 
Table I (Continued)

Intervention (n)

Subjects

\section{I = Intervention}

Outcome measures for

Author (date), country of origin

I = Intervention

C $=$ Control

depression or depressive

symptoms

Results

Caseness for

and study quality

$13=56$

breast care nurse (information

Blinding of investigators:

and counselling) $(n=70)$

Known confounders accounted for

$12=$ routine care plus

by study design: NO, cointerventions

not reported

Attrition of subjects and reasons:

YES Dropout rate: $17 \%$ overall

\section{education/information}

counselling/support from

voluntary organisation

routine care plus support from

voluntary organisation (offering

three types of support:

information, counselling and

regular group meetings with

fellow cancer suffers) $(n=66)$

$13=$ routine care plus

$13=$ routine care plus
education/information/

counselling/support from

nurse and organisation

$(n=69)$

$\mathrm{C}=$ routine care from ward

staff $(n=67)$

Psychotherapeutic studies (gynaecological cancer)

Burton et al (1995), UK
Design: Experimental randomised

controlled tria

Random allocation to treatment

groups: YES

Concealed treatment allocation: NO

Blinding of investigators: NO

Blinding of subjects: NO

Known confounders accounted for

by study design: NO, cointerventions not reported

Attrition of subjects and reasons:

Attrition unclear and no reasons

Petersen and Quinlivan (2002), Australia Design: Experimental randomied controlled trial

Random allocation to treatment

groups: YES

200 women awaiting

mastectomy for breast cancer Mean age (years)

$11=61$

$12=62$

$13=64$

$\mathrm{C}=57$

\section{II = Counselling}

psychotherapy: Individual symptoms

preoperative interview and a HADS, GHQ-28, PSE schedule

$30 \mathrm{~min}$ brief psychotherapeutic Measured at baseline, 4 days, 3

intervention $(n=50)$

Measured at baseline, 4 days, 3
months and I year after surgery

$12=$ Individual preoperative

interview and a 30 min 'chat' to

control for the effects of

attention $(n=50)$

$13=$ preoperative interview

only $(n=50)$

$\mathrm{C}=$ routine hospital care

control $(n=50)$

53 patients with

gynaecological cancer

Mean age (years) (s.d.):

$I=63.0(9.6)$

$C=61.2(13.5)$

Concealed treatment allocation: YES

Blinding of investigators: NO

Blinding of subjects: NO

Known confounders accounted for

by study design: NO, cointerventions

not reported

Attrition of subjects and reasons: YES

Dropout rate: 6\% overal

\section{I= Counselling/relaxation} I $\mathrm{h}$ relaxation and counselling interview performed by a

senior medical practitioner

involved in the patient's care.

The structured interview

consisted of listening to a

tape of relaxation music for

approx. $5 \mathrm{~min}$ followed by a

series of relaxation exercises

that lasted $20 \mathrm{~min}$. Patients

were encouraged to use the

techniques at home if they felt

stressed or anxious. The final

$30-35$ min was spent depression HADS GHQ-28
Depressive symptoms/

Measured at baseline and six

weeks

The intervention was associated with a significant reduction in total HADS score

$(P=0.002)$, reduction in HADS Mild/

moderate Depression subscale $(P=0.02)$,

and lower GHQ-28 scores $(P=0.03)$

No significant difference was found in

the fourth subscale of major depression
More control patients were cases for depression on PSE criteria at one year than patients in the experimenta groups $(P=0.037)$

ADS score case/noncase $(P=0.000 \mathrm{I})$ 
Table I (Continued)

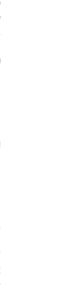

\begin{tabular}{lll}
\hline & Subjects & Intervention $(\boldsymbol{n})$ \\
$\begin{array}{l}\text { Author (date), country of origin } \\
\text { and study quality }\end{array}$ & $\begin{array}{l}\mathbf{I}=\text { Intervention } \\
\mathbf{C}=\text { Control }\end{array}$ & $\begin{array}{l}\mathbf{I}=\text { Intervention } \\
\mathbf{C}=\text { Control }\end{array}$ \\
\hline & & discussing the patient's \\
& condition $(n=27)$ \\
& $C=$ Patients were provided \\
& with all the normal \\
& postoperative support, \\
counselling and information \\
services provided by the \\
respective hospitals $(n=26)$
\end{tabular}

Psychotherapeutic studies (testicular cancer) Moynihan et al (1998), UK

Design: Experimental randomised controlled trial

Random allocation to treatment groups: YES

Concealed treatment allocation: YES

Blinding of investigators: YES

Blinding of subjects: NO

Known confounders accounted for by

study design: $\mathrm{NO}$, cointerventions

not reported

Attrition of subjects and reasons: YES

Dropout rate: $7 \%$ overall

Prostate cancer

Weber et al (2004), USA

Design: Experimental randomised

controlled trial

Random allocation to treatment

groups: YES

Concealed treatment allocation: NO

Blinding of investigators: NO

Blinding of subjects: NO

Known confounders accounted for

by study design: PARTIAL

Attrition of subjects and reasons:

YES Dropout rate: 0\%
73 men with newly diagnosed testicular cancer
I= CBT/PST: Adjuvant psychological therapy which uses both cognitive wh uses both cognitive and behavioural approaches includes strategies such as problem solving and regaining control. The intervention consisted of six individual sessions each lasting I $\mathrm{h}$ by a state registered mental health nurse who was experienced in caring for patients with testicular cancer $(n=36)$ $C=$ standard care $(n=37)$ support program - 10 men
= Social support: Peer of prostate cancer received

30 men who had recently undergone a radical prostatectomy for prostate cancer

Mean age (years) (s.d.)

$I=57.5(6.7)$

$C=59.7(6.6)$
Outcome measures for

depression or depressive

symptoms
Results

Caseness for

depression

\begin{tabular}{|c|c|c|}
\hline $\begin{array}{l}\text { Depression/depressive } \\
\text { symptoms } \\
\text { HADS } \\
\text { Measured at baseline 2, } 4\end{array}$ & HAD Depression scale, NS & $\begin{array}{l}\text { The proportion of patients } \\
\text { scoring above the threshold on } \\
\text { subscale was not influenced by } \\
\text { adjuvant psychological therapy }\end{array}$ \\
\hline
\end{tabular}

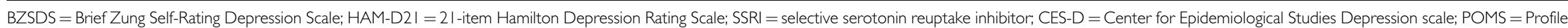

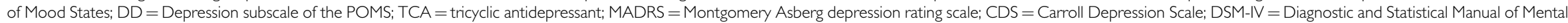

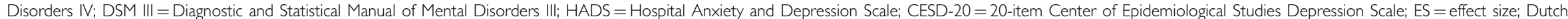

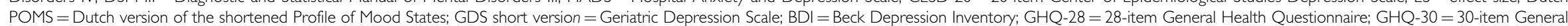

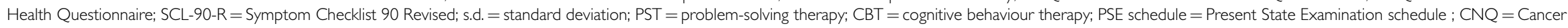
Needs Questionnaire - short form; EORTC QLQ-30 = European Organisation for Research and Treatment of Cancer Quality of Life Questionnaire C30.

Depressive symptoms GDS short versionAssessed 8 weeks
There was a significant difference in depression between groups at

4 weeks $(P=0.02)(E S=0.99)$, but ( decrease in GDS score for patients from baseline to 4 weeks was $88 \%$ in the experimental group and $0 \%$ in the control group 
Table 2 Methodological quality of included trials summary $(n=24)$

\begin{tabular}{|c|c|c|c|c|c|c|}
\hline \multirow[b]{2}{*}{ Quality indicator } & \multicolumn{3}{|c|}{ No. of pharmacological trials (\%) } & \multicolumn{3}{|c|}{ No. of psychotherapeutic trials (\%) } \\
\hline & Yes, fulfilled & No & Unclear & Yes, fulfilled & No & Unclear \\
\hline Random allocation to treatment groups - method sufficiently described & $6(100 \%)$ & - & - & $18(100 \%)$ & - & - \\
\hline Blinding of investigators & $5(83 \%)$ & | ( $17 \%)$ & - & $2(11 \%)$ & $16(89 \%)$ & - \\
\hline Blinding of subjects & $6(100 \%)$ & - & - & - & $18(100 \%)$ & - \\
\hline Concealed treatment allocation & $3(50 \%)$ & - & $3(50 \%)$ & $6(33 \%)$ & & $12(67 \%)$ \\
\hline \multicolumn{7}{|l|}{ Groups similar at baseline } \\
\hline Gender & $5(83 \%)$ & | (17\%) & - & $17(94 \%)$ & - & | (6\%) \\
\hline Age & $6(100 \%)$ & - & - & $13(72 \%)$ & $2(11 \%)$ & $3(17 \%)$ \\
\hline Ethnicity & $3(50 \%)$ & - & $3(50 \%)$ & $6(33 \%)$ & - & $12(67 \%)$ \\
\hline Disease distribution & $3(50 \%)$ & - & $3(50 \%)$ & $15(83 \%)$ & | (6\%) & $2(11 \%)$ \\
\hline Cancer treatment & $3(50 \%)$ & | (17\%) & $2(33 \%)$ & $10(55 \%)$ & | (6\%) & 7 (39\%) \\
\hline Depression/depressive symptoms & $6(100 \%)$ & - & - & $15(83 \%)$ & - & $3(17 \%)$ \\
\hline Screened for depression & $4(67 \%)$ & $2(33 \%)$ & - & $2(11 \%)$ & $16(89 \%)$ & - \\
\hline \multicolumn{7}{|l|}{ Cointerventions } \\
\hline Psychotherapeutic cointerventions avoided by trial design & - & $6(100 \%)$ & - & $2(11 \%)$ & $12(67 \%)$ & $4(22 \%)$ \\
\hline Psychotherapeutic cointerventions monitored & - & $6(100 \%)$ & - & $5(28 \%)$ & $9(50 \%)$ & $4(22 \%)$ \\
\hline Pharmacological cointerventions avoided by trial design & $5(83 \%)$ & I (I7\%) & - & - & $18(100 \%)$ & - \\
\hline Pharmacological cointerventions monitored & I ( $17 \%)$ & $5(83 \%)$ & & - & $18(100 \%)$ & - \\
\hline CAM interventions for depression avoided by trial design & - & $6(100 \%)$ & - & - & $18(100 \%)$ & - \\
\hline CAM interventions for depression monitored & - & $6(100 \%)$ & - & - & $18(100 \%)$ & - \\
\hline Clear description of intervention & $6(100 \%)$ & - & - & $18(100 \%)$ & - & - \\
\hline Outcome measures valid/reliable & $6(100 \%)$ & - & - & $18(100 \%)$ & - & - \\
\hline Reporting caseness for depression at follow-up & $3(50 \%)$ & $3(50 \%)$ & - & $5(28 \%)$ & $13(72 \%)$ & - \\
\hline \multicolumn{7}{|l|}{ Withdrawal } \\
\hline Attrition of subjects reported & $6(100 \%)$ & - & - & $16(89 \%)$ & $2(11 \%)$ & - \\
\hline Reasons reported & $6(100 \%)$ & - & - & $13(72 \%)$ & $5(28 \%)$ & - \\
\hline Sample size justification before study & $4(67 \%)$ & $2(33 \%)$ & - & $4(22 \%)$ & $14(78 \%)$ & - \\
\hline$N<1=100$ & $2(33 \%)$ & $4(67 \%)$ & - & $9(50 \%)$ & $9(50 \%)$ & - \\
\hline Intention-to-treat analyses stated & $3(50 \%)$ & $3(50 \%)$ & - & $6(33 \%)$ & $12(67 \%)$ & - \\
\hline
\end{tabular}

(12 and 14\%, respectively). Paroxetine was also found to be effective in reducing depressive symptoms in breast cancer patients undergoing chemotherapy (Roscoe et al, 2005).

Fluoxetine was found to be effective in reducing depressive symptoms in patients with advanced solid tumours (Fisch et al, 2003). Frequency of vomiting was significantly higher in patients receiving fluoxetine (nine of $27(33 \%)$ ) compared with patients receiving placebo (two of $43(4.6 \%)$ ), but there were significantly more fluoxetine patients receiving radiation therapy. Dropout rates were high with $54 \%$ for the intervention group and $44 \%$ for the controls.

There was a reduction in depressive symptoms in breast cancer patients who received mianserin compared with those receiving placebo (Van Heeringen and Zivkov, 1996). Tolerability appeared to be good with no significant differences between groups for adverse events and changes in vital signs. There were also significantly fewer dropouts from the intervention group $(21 \%)$ when compared to controls $(56 \%)(P=0.014)$.

\section{Psychotherapeutic studies}

Characteristics of the 18 included trials of psychotherapeutic interventions are shown in Table 1 . Studies were conducted in Europe $(n=5)$ (Burton et al, 1995; Marchioro et al, 1996; McArdle et al, 1996; Moynihan et al, 1998; Kuijer et al, 2004), the United States of America $(n=8)$ (Evans and Connis, 1995; Sandgren et al, 2000; Antoni et al, 2001; Classen et al, 2001; Rawl et al, 2002; Winzelberg et al, 2003; Given et al, 2004; Weber et al, 2004) Canada $(n=1)$ (Goodwin et al, 2001), Australia $(n=3)$ (Edelman et al, 1999; McLachlan et al, 2001; Petersen and Quinlivan, 2002) and Japan $(n=1)$ (Fukui et al, 2000). The mean sample size in the intervention and control group was 61 patients (range 15-296) and 52 patients (range 15-154), respectively. The average age of patients ranged from 49 to 64 years. The proportion of female participants ranged from between 41 to $100 \%$. Eight studies were multicentre trials (McArdle et al, 1996; Classen et al, 2001; Goodwin et al, 2001; McLachlan et al, 2001; Petersen and Quinlivan, 2002; Rawl et al, 2002; Given et al, 2004; Weber et al, 2004) and 10 were single-centre trials (Burton et al, 1995; Evans and Connis, 1995; Marchioro et al, 1996; Moynihan et al, 1998; Edelman et al, 1999; Fukui et al, 2000; Sandgren et al, 2000; Antoni et al, 2001; Winzelberg et al, 2003; Kuijer et al, 2004).

Methodological quality The methodological quality of these trials is summarised in Table 2. The sample size exceeded 100 in eight of 18 (44\%) trials (Burton et al, 1995; McArdle et al, 1996; Edelman et al, 1999; Classen et al, 2001; Goodwin et al, 2001; McLachlan et al, 2001; Rawl et al, 2002; Given et al, 2004). All studies randomly allocated subjects to treatment groups. Blinding of investigators was reported in two (11\%) trials (Moynihan et al, 1998; Goodwin et al, 2001). All 18 (100\%) studies provided a clear description of the intervention and had a representative source of subjects. Reporting of attrition of subjects was provided in $16(89 \%)$ studies and reasons for withdrawal in $13(72 \%)$ (see Table 1). Dropout rates for intervention and controls ranged from 0 to $41 \%$.

In all, 17 (94\%) studies were preventative, with subjects selected on the basis of a diagnosis of cancer and only one study selected patients with a diagnosis of depression according to DSM-III criteria (Evans and Connis, 1995). All outcome measures were clearly described and reliable. Only two (11\%) studies avoided some psychotherapeutic cointerventions by trial design (Goodwin 
et al, 2001; Weber et al, 2004). None of the trials reported avoiding or monitoring the use of pharmacological or CAM cointerventions.

Depression Only four of 18 (22\%) trials reported the efficacy of psychotherapeutic interventions in terms of caseness for depression (Burton et al, 1995; Moynihan et al, 1998; McLachlan et al, 2001; Petersen and Quinlivan, 2002). Of these, one found counselling/psychotherapy to be effective in reducing caseness for depression in breast cancer patients at 1 year follow-up $(P=0.037$; Burton et al, 1995), and another found counselling/ relaxation to be effective in reducing caseness for depression in gynaecological cancer at 6 weeks follow-up $(P=0.0001$; Petersen and Quinlivan, 2002). Computer-based assessments and individually tailored care plans were also associated with a reduction in the proportion of moderately or severely depressed cancer patients at 2 and 6 months follow-up (McLachlan et al, 2001); the statistical significance of this finding was not reported. However, in men newly diagnosed with testicular cancer, cognitive behaviour therapy/problem-solving therapy was not found to significantly reduce the proportion scoring above threshold for depression (Moynihan et al, 1998).

Depressive symptoms All 18 trials (100\%) reported the impact of psychotherapeutic interventions on the level of depressive symptoms as indicated by scores on questionnaires.

Cognitive behavioural therapy Several trials reported cognitive behavioural therapy (CBT) to be effective. CBT was found to reduce depressive symptoms in patients with breast, gastrointestinal, lymphoma, brain and lung cancers at 1 week postintervention $(\mathrm{ES}=0.55)$ (Kuijer et al, 2004), and also in depressed patients with lung, bladder, prostate and head-neck cancers receiving radiation treatment at 8 weeks follow-up $(P<0.01)$ (Evans and Connis, 1995). Efficacy was also reported for women with metastatic breast cancer immediately after completion of the intervention $(P=0.008)$ (Edelman et al, 1999); women newly treated for stage 0 - II breast cancer at 3 months postintervention, 6 and 12 months $(P<0.04)$ (Antoni et al, 2001); women with metastatic breast cancer assessed for depressive symptoms at 4,8 and 12 months $(\mathrm{ES}=0.27)($ Classen et al, 2001); and in metastatic breast cancer at 1 year $(P=0.002)$ (Goodwin et al, 2001). In addition, one study found CBT to have a short-term (10 weeks), but no long-term (20 weeks), effect on depressive symptoms in patients diagnosed with a solid tumour and receiving a first cycle of chemotherapy ( $\mathrm{ES}=0.25$ and 0.33 at 10 and 20 weeks, respectively) (Given $e t a l$, 2004). However, patients in the experimental group who entered with higher depressive symptoms had higher levels of depressive symptoms at 10 weeks than patients in the control group. Two other trials found CBT to have no significant effects on depressive symptoms in two studies of women with breast cancer (Fukui et al, 2000; Sandgren et al, 2000), but these both had sample sizes below 100 as compared to only two of the six studies that found CBT to be effective.

Counselling/psychotherapy Counselling/psychotherapy was found to be effective in reducing depressive symptoms in newly diagnosed women with nonmetastatic breast cancer assigned to adjuvant chemotherapy after surgery, with persistence over 9 months followup (ES $=0.27$, Marchioro et al, 1996). Counselling/relaxation was also found to be effective in reducing mild/moderate depressive symptoms 6 weeks after therapy in patients with gynaecological cancer (HADS mild/moderate depression subscale, $P=0.02$ ) but not severe levels of depressive symptoms (GHQ-28 Major depressive symptoms subscale, NS; Petersen and Quinlivan, 2002).

Supportive The provision of group social support was found to be as effective as CBT in reducing depressive symptoms in depressed patients with lung, bladder, prostate and head-neck cancer who were receiving radiation treatment, when assessed at 8 weeks $(P<0.01)$ and also effective at 6 months follow-up compared with controls $(P<0.01)$ (Evans and Connis, 1995). Peer support from long-term survivors of prostate cancer was found to be effective in reducing depressive symptoms in men who had recently undergone a radical prostatectomy when assessed at 4 weeks $(P=0.02)$, but not at 8 weeks, follow-up (Weber et al, 2004).

A web-based social support group was also found to be effective in reducing depressive symptoms in women with primary breast cancer when assessed at the end of the 12 weeks intervention $(\mathrm{ES}=0.54)$ (Winzelberg et al, 2003).

In a complex trial that compared different levels of support, routine care plus education/information/counselling/support from breast care nurse was found to be more effective than (1) routine care plus education/information/counselling/support from a voluntary organisation, (2) routine care plus education/information/ counselling/support from breast care nurse and voluntary organisation or (3) routine care from ward staff $(P=0.015$, $0.003,0.072$; McArdle et al, 1996). The failure to reduce morbidity in the combined group is difficult to explain.

Computer-based assessments and individually tailored care plans together with emotional support and counselling by nurses was found to reduce depressive symptoms midway through the intervention in newly diagnosed breast, colon or lung cancer patients who were receiving chemotherapy $(P=0.05)$ (Rawl et al, 2002). Computer-based assessments and individually tailored care plans were also found to reduce depressive symptoms $(P=0.001)$ at 6 months follow-up for patients with lung, head and neck, gynaecologic, haematology/lymphoma, melanoma and other types of cancers unspecified in the paper (McLachlan et al, 2001).

\section{DISCUSSION}

This systematic review indicates that there is limited trial data on the efficacy/tolerability of antidepressants and psychotherapeutic interventions for patients with cancer and depression. The reviewed studies varied in the type of pharmacological or psychotherapeutic interventions employed, the characteristics of the studied populations, the type, grade and stage of subjects' cancer, the treatments being received, and the trial design, including outcome measures used. Most were of small size and lacked control for possible confounding factors. Such limitations indicate the need for cautious interpretation of the review's findings beyond the contexts within which these studies were conducted.

\section{Pharmacological studies}

Only three of the six trials that involved pharmacological interventions reported the efficacy of antidepressants in terms of change in caseness for clinical depression as opposed to change scores indicating levels of depressive symptoms. Paroxetine was found to be effective in reducing major depression in patients with malignant melanoma who were to receive high-dose interferon alpha therapy (Musselman et al, 2001), and in reducing caseness for depression in breast cancer patients receiving chemotherapy (Roscoe et al, 2005). Fluoxetine was not effective in reducing caseness for depression in a trial that included patients with breast, gynaecological or haematological cancer (Razavi et al, 1996). However, the study by Razavi et al (1996) was only of brief duration (5 weeks) and higher doses of fluoxetine were not used.

Paroxetine and fluoxetine were both effective in reducing depressive symptoms in three trials that included patients with a range of cancers (breast, lung, haematological, gynaecological and gastrointestinal) (Fisch et al, 2003; Morrow et al, 2003; Roscoe et al, 2005), and the tetracyclic antidepressant mianserin was also 
shown to be effective in reducing depressive symptoms in breast cancer (Van Heeringen and Zivkov, 1996).

Some nonpsychological benefits of antidepressant therapy also emerged, such as improved adherence to cancer treatment. For example, paroxetine significantly decreased the likelihood that interferon alpha therapy in malignant melanoma would be discontinued because of severe depression or related neurotoxic effects (Musselman et al, 2001).

Although tolerability was only reported in four of the six pharmacological studies, overall, the tolerability of antidepressants in patients with cancer appears to be good. Although there was some evidence of adverse effects, these may well have been caused by other aspects of the treatment (e.g. radiotherapy, interferon alpha) that these patients were receiving.

\section{Psychotherapeutic interventions}

Only four of the reviewed studies reported the efficacy of psychotherapeutic interventions in treating depression. Of these, two trials reported significant benefits of counselling/psychotherapy (Burton et al, 1995) and counselling/relaxation (Petersen and Quinlivan, 2002) in reducing caseness for depression for patients with breast cancer and gynaecological cancer, respectively, and a third found computer-based assessment (including completion of the Beck Depression Inventory) and individually tailored care plans by a nurse to be associated with a reduction in the proportion of patients with moderate or severe depression (McLachlan et al, 2001).

There is more extensive evidence that psychotherapeutic interventions are effective in reducing depressive symptoms in cancer patients, at least in the short-term. Seven trials found cognitive behavioural therapy to be effective in reducing depressive symptoms, with persistence of improvement demonstrated for up to a year (Evans and Connis, 1995; Edelman et al, 1999; Antoni et al, 2001; Classen et al, 2001; Goodwin et al, 2001; Given et al, 2004; Kuijer et al, 2004). However, two trials found CBT to have no significant effects on depressive symptoms (Fukui et al, 2000; Sandgren et al, 2000), and one study found CBT to have a short-term (10 weeks), but no long-term (20 weeks), effect (Given et al, 2004).

Other psychotherapeutic approaches that may be effective in lowering depressive symptoms include supportive interventions in the form of social support groups, supportive dyads or web-based support groups (Evans and Connis, 1995; Winzelberg et al, 2003; Weber et al, 2004), computer-based assessments and individually tailored care plans (McLachlan et al, 2001; Rawl et al, 2002), and counselling/psychotherapy and counselling/relaxation (Burton et al, 1995; Marchioro et al, 1996).

\section{Methodological limitations}

A major limitation of all 24 trials reviewed was the lack of consistent avoidance/monitoring of the use of psychotherapeutic, pharmacological or CAM cointerventions by subjects. In general the reviewed studies had small sample sizes, and had not attempted to control for confounding, so limiting the validity of findings. Many patients being treated for cancer will be receiving care from a variety of primary-, secondary- and tertiary-care clinicians. Many patients also make use of CAM to manage their condition (Tatsumura et al, 2003; McClain-Jacobson et al, 2004; Montazeri et al, 2005), and there are CAM approaches associated with decreasing depression/depressive symptoms in cancer patients (Targ and Levine, 2002; Fellowes et al, 2004; Cohen et al, 2005; Rajasekaran et al, 2005). Such confounding factors can be controlled for at the stage of data analysis, but this requires adequate numbers of subjects to have been recruited into trials and data on cointerventions to have been collected. While this review was limited to non-CAM interventions, the same need for rigour and control of confounding factors would apply to this body of research.

A large proportion of the psychotherapeutic studies were singlecentre trials, so limiting the generalisability of findings beyond the context of the trial setting. Psychotherapeutic interventions are likely to be highly dependent on the practitioners' training, skills and other attributes. Hence, multicentre trials are needed to confirm the applicability and effectiveness of interventions. Furthermore, many of the studies report findings that only just achieve statistical significance, suggesting the likelihood of publication bias that needs to be considered in the interpretation of their findings.

There was only one trial that selected patients on the basis of a diagnosis of depression (Evans and Connis, 1995), but the change in caseness for depression was not reported in this study. The negative findings of some studies may reflect that recruited subjects did not have significant psychological morbidity; psychotherapeutic and pharmacological interventions should be offered to patients with clinically meaningful levels of depression/ depressive symptoms.

Given the small number of studies on the efficacy on antidepressants with cancer patients in general, there is a need for further work with specific groups of cancer patients. Tolerability data were not always recorded and reported. It is important that future studies include recording and reporting of adverse effects, especially as such effects are likely to have an impact on compliance (Stokes, 1993). Concerns that antidepressants may lead to or accelerate the development of cancer also need further investigation (Brandes et al, 1992; Wallace et al, 2001).

Finally, while the randomised controlled studies in this review may be of relevance to palliative care, no studies were conducted with palliative care patients as subjects. Controlled studies including such subjects are even more difficult to conduct than those on nonpalliative cancer patients. Depression is difficult to diagnose in such patients, and depressive symptoms are very similar to the general symptoms of end-stage cancer. While high attrition rates, together with high heterogeneity, would lead to the need for very large sample sizes, recruitment is difficult for practical and ethical reasons (Grande and Todd, 2000; AddingtonHall, 2002). There is also a lack of reporting on syndromal depression and this too requires further work.

\section{CONCLUSION}

The sparse number of studies of pharmacological interventions for cancer patients with depression provides some evidence that antidepressants are effective in reducing depression/depressive symptoms in cancer patients. Although more data are needed regarding the safety and efficacy of antidepressants, there is some evidence that cancer patients with depression are responsive to treatment. Overall, the small number of trials of pharmacological interventions for cancer patients with depression/depressive symptoms, high dropout rates in some trials and lack of reporting of adverse events/tolerability should caution against drawing definitive conclusions about which antidepressants are most effective or well tolerated by cancer patients in general or by patients with specific types of cancer.

There is limited trial data on the efficacy of psychotherapeutic interventions in treating depression/depressive symptoms in cancer patients. Cognitive behavioural therapy appears to be effective in reducing depressive symptoms in cancer patients. Social support for cancer patients may also be effective in reducing depressive symptoms.

However, there is a need for more rigorous investigation of the efficacy of both pharmacological and psychotherapeutic interventions, including avoidance/monitoring of the confounding factors 
of the use of other pharmacological/psychotherapeutic and CAM cointerventions by subjects. In addition, there is also a need for studies comparing the efficacy of psychotherapeutic $v s$ pharmacological interventions. With the known side effects and the controversies about the possible stimulation of malignant growth by antidepressant drugs, there is a need for careful and rigorous investigation of the efficacy of pharmacological treatment for depression in cancer patients and more importantly of possible psychotherapeutic alternatives (Wallace et al, 2001).

Finally, the current lack of clinical trial data to robustly demonstrate efficacy is not synonymous with evidence of ineffectiveness. It would be entirely inappropriate to use the findings of this review to deny patients with cancer access to treatment for depression and depressive symptoms because of a lack of trial data on effectiveness. The review indicates that there remains a pressing need for more thorough and extensive investigation of the effectiveness and consequences of different approaches to managing depression in cancer patients to inform the design and delivery of effective healthcare services.

\section{ACKNOWLEDGEMENTS}

We thank Antje Lindenmeyer for help with literature retrieval. Contributors: SW and JD acquired and interpreted the findings. SW will act as guarantor. Both authors critically revised the systematic review.

\section{REFERENCES}

Addington-Hall J (2002) Research sensitivities to palliative care patients. Eur J Cancer Care 11: 220-224

Andersen BL, Farrar WB, Golden-Kreutz D, Kutz LA, MacCallum R, Courtney ME, Glaser R (1998) Stress and immune responses after surgical treatment for regional breast cancer. J Natl Cancer Inst 90: $30-36$

Antoni MH, Lehman JM, Kilbourn KM, Boyers AE, Culver JL, Alferi SM, Yount SE, McGregor BA, Arena PL, Harris SD, Price AA, Carver CS (2001) Cognitive-behavioural stress management intervention decreases the prevalence of depression and enhances benefit finding among women under treatment for early stage breast cancer. Health Psychol 20: 20-32

Bailey RK, Geyen DJ, Scott-Gurnell K, Hipolito MMS, Bailey TA, Beal JM (2005) Understanding and treating depression among cancer patients. Int J Gynecol Cancer 15: 203-208

Barsevick AM, Sweeney C, Haney E, Chung E (2002) A systematic qualitative analysis of psychoeducational interventions for depression in patients with cancer. Oncol Nurs Forum 29: 73-84

Brandes LJ, Arron RJ, Bogdanovic RP, Tong J, Zaborniak CL, Hogg GR, Warrington RC, Fang W, LaBella FS (1992) Stimulation of malignant growth in rodents by antidepressant drugs at clinically relevant doses. Cancer Res 52: 3796-3800

Buccheri G (1998) Depressive reactions to lung cancer are common and often followed by a poor outcome. Eur Respir J 11: 173-178

Burton MV, Parker RW, Farrell A, Bailey D, Conneely J, Booth S, Elcombe S (1995) A randomised controlled trial of preoperative psychology preparation for mastectomy. Psycho-Oncology 4: 1-19

Chalmers I, Haynes B (1994) Systematic reviews: reporting, updating and correcting systematic reviews of the effects of health care. BMJ 309: $826-865$

Cho MK, Bero LA (1994) Instruments for assessing the quality of drug studies published in the medical literature. JAMA 13: 272:101-104

Classen C, Butler LD, Koopman C, Miller E, DiMiceli S, Giese-Davis J, Fobair P, Carlson RW, Kraemer HC, Spiegel D (2001) Supportiveexpressive group therapy and distress in patients with metastatic breast cancer: a randomized clinical intervention trial. Arch Gen Psychiatry 58: $494-501$

Cohen AJ, Menter A, Hale L (2005) Acupuncture: role in comprehensive cancer care-a primer for the oncologist and review of the literature. Integr Cancer Ther 4: $131-143$

Devine EC, Westlake SK (1995) The effects of psychoeducational care provided to adults with cancer: meta-analysis of 116 studies. Oncol Nurs Forum 22: 1369-1381

Edelman S, Lemon J, Bell DR, Kidman AD (1999) Effects of group CBT on the survival time of patients with metastatic breast cancer. PsychoOncology 8: 474-481

Evans RL, Connis RT (1995) Comparison of brief group therapies for depressed cancer patients receiving radiation treatment. Public Health Rep 110: 306-311

Faller H, Bulzebruck $\mathrm{H}$ (2002) Coping and survival in lung cancer: a 10 year follow-up. Am J Psychiatr 159: 2105-2107

Faller H, Bulzebruck H, Drings P, Lang H (1999) Coping, distress and survival among patients with lung cancer. Arch Gen Psychiatr 56: $756-762$

Fellowes D, Barnes K, Wilkinson S (2004) Aromatherapy and massage for symptom relief in patients with cancer. Cochrane Database of Systematic Reviews, (Online: update software) CD002287

Fisch MJ, Loehrer PJ, Kristeller J, Passik S, Jung SH, Shen J, Arquette MA, Brames MJ, Einhorn LH (2003) Fluoxetine versus placebo in advanced cancer outpatients: a double-blinded trial of the Hoosier Oncology Group. J Clin Oncol 21: 1937-1943

Fukui S, Kugaya A, Okamura H, Kamiya M, Koike M, Nakanishi T, Imoto S, Kanagawa K, Uchitomi Y (2000) A psychosocial group intervention for Japanese women with primary breast carcinoma: a randomized controlled trial. Cancer 89: 1026-1036

Given C, Given B, Rahbar M, Jeon S, McCorkle R, Cimprich B, Galecki A, Kozachik S, Devoss D, Brady A, Fisher-Malloy MJ, Courtney K, Bowie E (2004) Does a symptom management intervention affect depression among cancer patients: results from a clinical trial. Psycho-Oncology 13: $818-830$

Goodwin PJ, Leszcz M, Ennis M, Koopmans J, Vincent L, Guther H, Drysdale E, Hundleby M, Chochinov HM, Navarro M, Speca M, Hunter J (2001) The effect of group psychosocial support on survival in metastatic breast cancer. N Engl J Med 345: 1719-1726

Goodwin JS, Zhang DD, Ostir GV (2004) Effect of depression on diagnosis, treatment and survival of older women with breast cancer. J Am Geriatr Soc 52: $106-111$

Grande GE, Todd C (2000) Why are trials in palliative care so difficult? Palliat Med 14: 69-74

Herjl K, Andersen EW, Keiding N, Mouridsen HT, Mortensen PB, Jorgensen T (2003) Depression as a prognostic factor for breast cancer mortality. Psychosomatics 44: 24-30

Holland JC, Romano SJ, Heiligenstein JH, Tepner RG, Wilson MG (1998) A controlled trial of fluoxetine and desipramine in depressed women with advanced cancer. Psycho-Oncology 7: 291-300

Kissane DW, Bloch S, Smith GC, Miach P, Clarke DM, Ikin J, Love A, Ranieri N, McKenzie D (2003) Cognitive-existential group psychotherapy for women with primary breast cancer: a randomised controlled trial. Psycho-Oncology 12: 532-546

Kuijer RG, Buunk BP, Jong M, Ybema JF, Sanderman R (2004) Effects of a brief intervention program for patients with cancer and their partners on feelings of inequity, relationship quality and psychological distress. Psycho-Oncology 13: $321-334$

Lloyd-Williams M (2000) Difficulties in diagnosing and treating depression in the terminally ill cancer patient. Postgrad Med J 76: 555-558

Lloyd-Williams M (2001) Screening for depression in palliative care patients: a review. Eur J Cancer 10: $31-35$

Marchioro G, Azzarello G, Checchin F, Perale M, Segati R, Sampognaro E, Rosetti F, Franchin A, Pappagallo GL, Vinante O (1996) The impact of a psychological intervention on quality of life in non-metastatic breast cancer. Eur J Cancer 32: 1612 - 1615

Massie MJ (2004) Prevalence of depression in patients with cancer. J Natl Cancer Inst Monogr 32: 57-71

McArdle JM, George WD, McArdle CS, Smith DC, Moodie AR, Hughson AV, Murray GD (1996) Psychological support for patients undergoing breast cancer surgery: a randomised study. $B M J$ 312: 813-816

McClain-Jacobson C, Rosenfeld B, Kosinki A, Pessin H, Cimino JE, Breitbart W (2004) Belief in an afterlife, spiritual well-being and end-of- 
life despair in patients with advanced cancer. Gen Hosp Psychiatry 26: 484-486

McLachlan SA, Allenby A, Matthews J, Wirth A, Kissane D, Bishop M, Beresford J, Zalcberg J (2001) Randomized trial of coordinated psychosocial interventions based on patient self-assessments versus standard care to improve the psychosocial functioning of patients with cancer. J Clin Oncol 19: 4117-4125

Meyer TJ, Mark MM (1995) Effects of psychosocial interventions with adult cancer patients: a meta-analysis of randomised experiments. Health Psychol 14: $101-108$

Montazeri A, Sajadian A, Ebrahimi M, Akbari ME (2005) Depression and the use of complementary medicine among breast cancer patients. Support Cancer Care 13: 339-342

Morrow GR, Hickok JT, Roscoe JA, Raubertas RF, Andrews PLR, Flynn PJ, Hynes HE, Banerjee TK, Kirshner JJ, King DK (2003) Differential effects of paroxetine on fatigue and depression: a randomized double-blind trial from the University of Rochester Cancer Centre Community Clinical Oncology Program. J Clin Oncol 21: $4635-4641$

Moynihan C, Bliss JM, Davidson J, Burchell L, Horwich A (1998) Evaluation of adjuvant psychological therapy in patients with testicular cancer: randomised controlled trial. BMJ 316: 429-435

Mulrow CD (1994) Systematic reviews: rationale for systematic reviews. BMJ 309: 597 - 599

Musselman DL, Lawson DH, Gumnick JF, Manatunga AK, Penna S, Goodkin RS, Greiner K, Nemeroff CB, Miller AH (2001) Paroxetine for the prevention of depression induced by high-dose interferon alfa. $N$ Engl J Med 344: 961 - 966

Newell SA, Sanson-Fisher RW, Savolainen NJ (2002) Systematic review of psychological therapies for cancer patients: overview and recommendations for future research. JNCI Cancer Spectrum 94: 558-584

Newport DJ, Nemeroff CB (1998) Assessment and treatment of depression in the cancer patient. J Psychosomat Res 45: 215-237

NICE, National Institute for Clinical Excellence (2004) Depression: management of depression in primary and secondary care. Clinical Guideline 23, December 2004

Oxman AD (1994) Systematic reviews: checklists for review articles. BMJ 309: $648-651$

Passik SD, Dugan W, McDonald MV, Rosenfeld B, Theobald DE, Edgerton $S$ (1998) Oncologists' recognition of depression in their patients with cancer. J Clin Oncol 16: $1594-1600$

Petersen RW, Quinlivan JA (2002) Preventing anxiety and depression in gynaecological cancer: a randomised controlled trial. $\mathrm{Br} J$ Obstet Gynaecol 109: 386-394

Petito JM, Evans DL (1998) Depression in cancer and HIV infection: research findings and implications of effective antidepressant treatment. Depress Anxiety 8: 80-84

Rajasekaran M, Edmonds PM, Higginson IL (2005) Systematic review of hypnotherapy for treating symptoms in terminally ill adult cancer patients. Palliat Med 19: 418-426

Rawl SM, Given BA, Given CW, Champion VL, Kozachik SL, Barton D, Emsley CL, Williams SD (2002) Intervention to improve psychological functioning for newly diagnosed patients with cancer. Oncol Nurs Forum 29: $967-975$

Razavi D, Allilaire JF, Smith M, Salimpour A, Verra M, Desclaux B, Saltel P, Piollet I, Gauvain-Piquard A, Trichard C, Cordier B, Fresco R, Guillibert E, Sechter D, Orth JP, Bouhassira M, Mesters P, Blin P (1996) The effect of fluoxetine on anxiety and depression symptoms in cancer patients. Acta Psychiatr Scand 94: 205-210

Reiche EMV, Nunes SOV, Morimoto HK (2004) Stress, depression, the immune system and cancer. Lancet Oncol 5: 617-625

Roscoe JA, Morrow GR, Hickok JT, Mustian KM, Griggs JJ, Matteson SE, Bushunow P, Qazi R, Smith B (2005) Effect of paroxetine hydrochloride (Paxil) on fatigue and depression in breast cancer patients receiving chemotherapy. Breast Cancer Res Treat 89: 243-249

Sandgren AK, McCaul KD, King B, O'Donnell S, Foreman G (2000) Telephone therapy for patients with breast cancer. Oncol Nurs Forum 27: 683-688

Sharpe M, Strong V, Allen K, Rush R, Postma K, Tulloh A, Maguire P, House A, Ramirez A, Cull A (2004) Major depression in outpatients attending a regional cancer centre: screening and unmet treatment needs. Br J Cancer 90: 314-320

Sheard T, Maguire P (1999) The effect of psychological interventions on anxiety and depression in cancer patients: results of two meta-analyses. Br J Cancer 80: 1770 - 1780

Somerset W, Stout SC, Miller AH, Musselman D (2004) Breast cancer and depression. Oncology (Huntington) 18: 1021-1023

Stiegelis HE, Hagedoorn M, Sanderman R, Bennenbroek FT, Buunk BP, van den Bergh AC, Botke G, Ranchor AV (2004) The impact of an informational self-management intervention on the association between control and illness uncertainty before and psychological distress after radiotherapy. Psycho-Oncology 13: 248-259

Stokes PE (1993) Fluoxetine: a five year review. Clin Ther 15: $216-243$

Targ EF, Levine EG (2002) The efficacy of a mind-body-spirit group for women with breast cancer: a randomized controlled trial. Gen Hosp Psychiatry 24: 238-248

Tatsumura Y, Maskarinec G, Shumay DM, Kakai H (2003) Religious and spiritual resources, CAM and conventional treatment in the lives of cancer patients. Altern Ther Health Med 9: 64-67

Turner J, Zapart S, Pedersen K, Rankin N, Luxford K, Fletcher J (2005) Clinical practice guidelines for the psychosocial care of adults with cancer. Psycho-Onoclogy 14: 159-173

Uitterhoeve RJ, Vernooy M, Litjens M, Potting K, Bensing J, De Mulder P, van Achterberg T (2004) Psychosocial interventions for patients with advanced cancer - a systematic review of the literature. Br J Cancer 91: $1050-1062$

Van Heeringen K, Zivkov M (1996) Pharmacological treatment of depression in cancer patients. A placebo-controlled study of mianserin. Br J Psychiatry 169: $440-443$

Wallace WA, Balsitis M, Harrison BJ (2001) Male breast neoplasms in association with selective serotonin re-uptake inhibitor therapy: a report of three cases. Eur J Surg Oncol 27: 4429-4431

Watson M, Haviland JS, Greer S, Davidson J, Bliss JM (1999) Influence of psychological response on survival in breast cancer: a population based cohort study. Lancet 354: $1331-1336$

Weber BA, Roberts BL, Resnick M, Deimling G, Zauszniewski JA, Musil C, Yarandi HN (2004) The effect of dyadic intervention on self-efficacy, social support and depression for men with prostate cancer. PsychoOncology 13: 47-60

Winzelberg AJ, Classen C, Alpers GW, Roberts H, Koopman C, Adams RE, Ernst H, Dev P, Taylor CB (2003) Evaluation of an Internet support group for women with primary breast cancer. Cancer 97: 1164-1173 


\section{Appendix A}

Data Extraction Form Methodological Quality Instrument (Cho and Bero, 1994) (Table A1).

\section{Table Al}

Reviewer

Article

I. Study design (choose I only):

Experimental randomised:

Placebo-controlled trial

Controlled trial

Comparative trial, no placebo

Time series trial

Crossover trial

Experimental, unrandomised:

Placebo controlled tria

Comparative trial, no placebo

Time series trial

Crossover trial

Natural experiment

Nonexperimental:

Cohort, prospective

Cohort, retrospective

Cross-sectional

Case-control

Case reports or case series

None of the above (describe):

2. What was the study question? (please use space below)

3. Was the study question sufficiently described?

4. Was the study design appropriate to answer the study question?

5. Were both inclusion and exclusion criteria specified? (If case study, check N/A)

6. For case studies only: Were patient characteristics adequately reported? (If not case study, check N/A.)

7. Were subjects appropriate to the study question?

8. Were control subjects appropriate? (If no controls were used, check No).

9. Were subjects randomly selected from the target population?

10. If subjects were randomly selected, was the method of random selection sufficiently well described? (If subjects were not randomly selected, check N/A).

1 I. If subjects were randomly allocated to treatment groups, was the method of random allocation sufficiently described? (If subjects were not randomly allocated, check N/A).

12. If blinding of investigators to intervention was possible, was it reported? (If not possible check N/A).

13. If blinding of subjects to intervention was possible, was it reported? (If not possible, check N/A).

14. Was measurement bias accounted for by methods other than blinding?

15. Were known confounders accounted for by study design? (If no known confounders, check N/A)

16. Were known confounders accounted for by analysis? (If no known confounders, check N/A).

17. Was there a sample size justification before the study?

18. Were post hoc power calculations or confidence intervals reported for statistically nonsignificant results?

19. Were statistical analyses appropriate?

20. Were statistical tests stated?

21. Were exact $P$ values or confidence intervals reported for each test?

22. Were attrition of subjects and reason for attrition recorded?

23. For those subjects who completed the study, were results completely reported?

24. Do the findings support the conclusions? 
Effectiveness of treatment for depression/depressive symptoms

S Williams and J Dale

Data Extraction Form: Pharmacological intervention/psychosocial intervention (Table A2).

Table A2

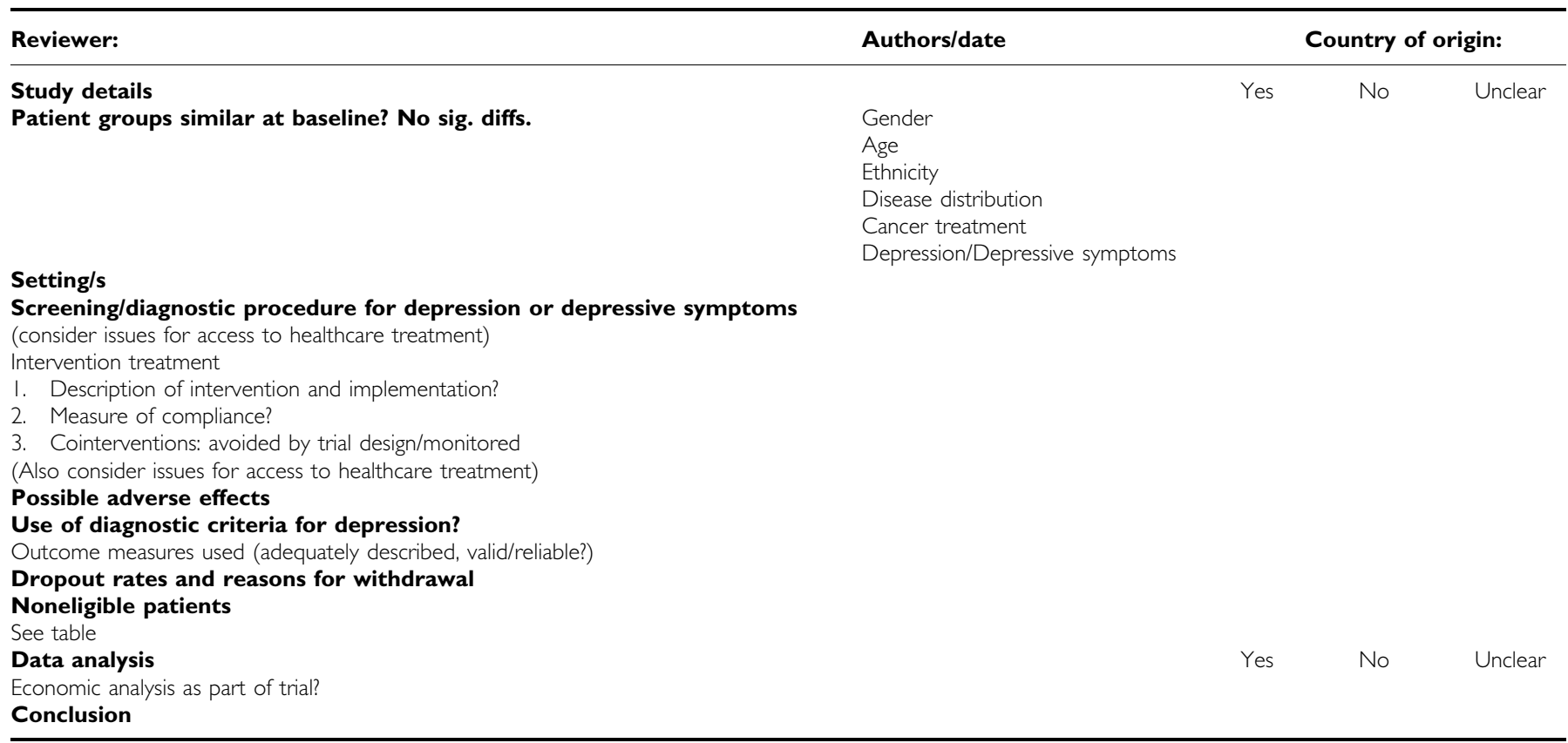

